\title{
Evidence for a Role of Collagen Synthesis in Arterial Smooth Muscle Cell Migration
}

\author{
Edward F. Rocnik, Bosco M.C. Chan, ${ }^{\star}$ and J. Geoffrey Pickering \\ John P. Robarts Research Institute, Vascular Biology Group, London Health Sciences Centre, Department of Medicine (Cardiology), \\ Department of Biochemistry, Department of Medical Biophysics, and *Department of Microbiology and Immunology, University of \\ Western Ontario, London, Canada N6A $5 K 8$
}

\begin{abstract}
Migration of smooth muscle cells (SMCs) and collagen synthesis by SMCs are central to the pathophysiology of vascular disease. Both processes can be induced shortly after vascular injury; however, a functional relationship between them has not been established. In this study, we determined if collagen synthesis was required for SMC migration, using ethyl-3,4-dihydroxybenzoate (EDHB), an inhibitor of prolyl-4-hydroxylase, and 3,4-DL-dehydroproline (DHP), a proline analogue, which we demonstrate inhibit collagen elaboration by porcine arterial SMCs. SMCs exposed to EDHB or DHP attached normally to collagen- and vitronectin-coated substrates; however, spreading on collagen but not vitronectin was inhibited. SMC migration speed, quantified by digital time-lapse video microscopy, was significantly and reversibly reduced by EDHB and DHP. Flow cytometry revealed that expression of $\beta 1$ integrins, through which SMCs interact with collagen, was unaffected by EDHB or DHP. However, both inhibitors prevented normal clustering of $\beta 1$ integrins on the surface of SMCs, consistent with a lack of appropriate matrix ligands for integrin engagement. Moreover, there was impaired recruitment of vinculin into focal adhesion complexes of spreading SMCs and disassembly of the smooth muscle $\alpha$-actin-containing cytoskeleton. These findings suggest that de novo collagen synthesis plays a role in SMC migration and implicates a mechanism whereby newly synthesized collagen may be necessary to maintain the transcellular traction system required for effective locomotion. (J. Clin. Invest. 1998. 101:1889-1898.) Key words: muscle, smooth, vascular • cell movement • integrins • extracellular matrix proteins $\bullet$ actins
\end{abstract}

\section{Introduction}

Migration of vascular smooth muscle cells (SMCs) ${ }^{1}$ is a fundamental aspect of arterial restructuring. Translocation of SMCs

Address correspondence to J. Geoffrey Pickering, M.D., Ph.D., London Health Sciences Centre, 339 Windermere Rd., London, Ontario Canada N6A 5A5. Phone: 519-663-3973; FAX: 519-434-3278; E-mail: gpickrng@rri.uwo.ca

Received for publication 24 June 1997 and accepted in revised form 25 February 1998.

1. Abbreviations used in this paper: DHP, 3,4-DL-dehydroproline; ECM, extracellular matrix; EDHB, ethyl-3,4-dihydroxybenzoate; SMC, smooth muscle cell.

J. Clin. Invest.

(C) The American Society for Clinical Investigation, Inc. 0021-9738/98/05/1889/10 \$2.00

Volume 101, Number 9, May 1998, 1889-1898

http://www.jci.org from the media to the intima, or within the intima, is considered to be critical to atherogenesis (1), to restenosis formation after balloon angioplasty (2), and to repair of disrupted atherosclerotic plaque (3). Environmental signals that can regulate SMC migration include growth factors such as plateletderived growth factor $(4,5)$, fibroblast growth factor-2 $(6,7)$, and transforming growth factor- $\beta(8,9)$. SMC locomotion may also be controlled by components of the extracellular matrix (ECM) including fibrinogen and fibrin (10), fibronectin (11), and hyaluronic acid (12).

Collagens are among the most abundant ECM proteins of the normal and diseased vessel wall (13-17). They can exist as a meshwork surrounding individual SMCs (type IV or basement membrane collagen) or as interstitial dense fibers that occupy a substantial volume of the tissue (type I and III fibrillar collagens) (16). In each of these biochemical and structural forms, the collagen network can be expected to serve as a mechanical barrier to SMC migration. However, there is also evidence that collagens can be effective substrates for SMC motility. It is well established, for example, that type I collagen is a suitable substrate for SMC migration in vitro (18), superior in some circumstances to vitronectin (19) and fibronectin (6). Furthermore, growth factor-mediated SMC migration on type I collagen has been shown in two studies to be dependent on the $\alpha 2 \beta 1$ integrin-type collagen receptor $(6,18)$.

Although there is abundant collagen in the normal vessel wall, vascular cells are induced to synthesize new collagen shortly after arterial injury. Strauss and co-workers observed increased collagen synthesis $1 \mathrm{wk}$ after angioplasty to the rabbit iliac artery (20). Similarly, increased expression of type I (21) and type VIII (22) collagen have been detected during the first week after balloon injury to the rat carotid artery. Expression of collagens at these relatively early times after injury coincides with SMC migration into the intima and lesion formation $(23,24)$. These expression data thus raise the possibility that de novo production of collagen by SMCs, perhaps in concert with degradation of preexisting collagen, may be important in establishing a suitable extracellular environment for SMC migration. To date, however, it has not been determined whether there is a specific need for new collagen production in SMC migration.

Hydroxylation of proline is a key step in the collagen synthesis pathway. A critical number of prolyl residues in $\alpha$ chains of procollagen must be hydroxylated in order for the nascent pro- $\alpha$ chains to fold into a stable triple helical conformation. Triple helix formation, in turn, is necessary for normal secretion of procollagen into the extracellular milieu. This requirement for proline hydroxylation is the basis for the design of pharmacological inhibitors of collagen accumulation $(25,26)$. One class of such compounds serves as competitive inhibitors of prolyl-4-hydroxylase, the enzyme that catalyzes the hydroxylation reaction $(27,28)$. A second class of inhibitors consists of structural analogues of proline which incorporate into pro- $\alpha$ collagen chains but, because they are not substrates for prolyl- 
4-hydroxylase, do not become hydroxylated (29). Both types of agents have been shown to markedly impair the secretion of functional collagen $(27,29,30)$.

In this study, we have used both classes of collagen synthesis inhibitors to address the question of the need for endogenous collagen production in SMC migration. Our results indicate that ethyl-3,4-dihydroxybenzoate (EDHB), an inhibitor of prolyl-4-hydroxylase, and 3,4-DL-dehydroproline (DHP), a proline analogue, reversibly inhibit in vitro migration of arterial SMCs. Furthermore, we demonstrate that SMCs incubated with collagen synthesis inhibitors fail to cluster $\beta 1$ integrins and to form focal adhesion contacts at their periphery, while spreading over an ECM substrate. Moreover, inhibition of collagen synthesis in SMCs led to complete disassembly of the smooth muscle $\alpha$-actin-containing cytoskeleton. The actions were not attributable to toxic effects of the reagents and were similar with the two mechanistically distinct collagen synthesis inhibitors. These findings indicate that locomotion of SMCs requires de novo collagen synthesis and implicate a mechanism whereby newly synthesized collagen is required for integrin clustering and linkage to the cytoskeleton, so that movement can effectively proceed.

\section{Methods}

Reagents, antibodies, and adhesive ligands. EDHB and DHP were purchased from Sigma Chemical Co. (St. Louis, MO). Type I collagen elaboration was probed using LF 67, rabbit antiserum to the C-telopeptide region of the $\alpha 1(\mathrm{I})$ chain of human type I collagen (gift of Dr. L.W. Fisher, National Institute of Dental Research, Bethesda, MD) $(31,32)$. $\beta 1$ integrin expression was studied using anti-human $\beta 1$ integrin subunit specific mAb HB1.1 (Chemicon Inc., Temecula, CA), which we established cross-reacts with porcine $\beta 1$ integrin. Other mAbs used included antivinculin mAb VIN-11-5 (Sigma), and a mAb against smooth muscle $\alpha$-actin (clone 1A4; Dako, Glostrup, Denmark). Flow cytometry was performed using an isotype-matched control antibody (P3; American Type Culture Collection, Rockville, MD). Rat tail collagen solubilized in acetic acid was used as a source of type I collagen and was prepared as described previously (33). Human fibronectin was isolated from human plasma by gelatinSepharose chromatography (34). Vitronectin was purchased from Life Technologies, Inc. (Gaithersburg, MD).

Cell culture. Primary cultures of vascular SMCs were isolated by enzymatic dispersion of porcine carotid arteries retrieved from a local abattoir using modifications of previously described methods (35). Before dispersion, the adventitia and outer one-third of the media were discarded and endothelial cells were removed by scraping. Arterial strips were then incubated in dissociation medium containing 0.8 $\mathrm{mg} / \mathrm{ml}$ collagenase (Sigma blend type $\mathrm{H}$ ), $1 \mathrm{mg} / \mathrm{ml}$ papain, $1.2 \mathrm{mg} / \mathrm{ml}$ BSA, $0.09 \mathrm{mg} / \mathrm{ml}$ DTT, and $0.25 \mathrm{mM}$ EDTA in PBS pH 7.0 for, sequentially, $6 \mathrm{~h}$ at $4^{\circ} \mathrm{C}, 30 \mathrm{~min}$ at room temperature, and $2 \mathrm{~h}$ at $35^{\circ} \mathrm{C}$. Identity of SMCs in culture was confirmed by positive immunostaining for smooth muscle $\alpha$-actin. Cells were maintained in DME (Life Technologies, Inc.) supplemented with $4 \%$ fetal bovine serum, unless otherwise indicated, and were studied in the second to fourth subcultures.

Collagen production by Western blot analysis. SMCs were incubated with either EDHB or DHP and media were harvested with phenylmethylsulfonyl fluoride $(0.1 \mathrm{mM})$ and leupeptin $(10 \mu \mathrm{g} / \mathrm{ml})$. Total protein content of conditioned media was measured by Lowry assay (Biorad Canada, Mississauga, Ontario, Canada). Samples were mixed with an equal volume of $2 \times$ SDS gel loading buffer $(100 \mathrm{mM}$ Tris-Cl, pH 6.8, 4\% SDS, $20 \%$ glycerol, $200 \mathrm{mM} \mathrm{DTT,} 0.2 \%$ bro- mophenol blue) and equal amounts of protein were resolved on $6 \%$ (for collagen) or $15 \%$ (for smooth muscle $\alpha$-actin) polyacrylamide gels under reducing conditions. Proteins were transferred electrophoretically to a PVDF membrane (Immobilon P; Millipore Corp., Bedford, MA). After overnight blocking, membranes were incubated with the designated primary antibody for $3 \mathrm{~h}$ at room temperature. Primary antibodies used were LF 67 (for type I collagen) and $\mathrm{mAb}$ $1 \mathrm{~A} 4$ (for smooth muscle $\alpha$-actin). Bound primary antibody was reacted with anti-rabbit peroxidase-conjugated IgG or anti-mouse peroxidase-conjugated Fab fragments for $1 \mathrm{~h}$ and detected by chemiluminescence, according to the manufacturer's recommendations (Boehringer Mannheim, Laval, Quebec, Canada). Washed blots were exposed to x-ray film (XAR-5; Eastman Kodak, Rochester, NY).

Attachment and spreading assays. SMCs treated for $4 \mathrm{~d}$ with either EDHB $(400 \mu \mathrm{M})$ or DHP $(1 \mathrm{mM})$ were detached with trypsinEDTA and subsequent attachment to matrix-coated substrates was evaluated as previously described (36). Briefly, SMCs were resuspended in serum-free DME containing $1 \%$ BSA, and cells $(10,000$ cells $/ \mathrm{cm}^{2}$ ) were seeded on glass coverslips that had been precoated overnight at $4^{\circ} \mathrm{C}$ with the adhesive ligands $(15 \mu \mathrm{g} / \mathrm{ml}$ for collagens and fibronectin, $1 \mu \mathrm{g} / \mathrm{ml}$ for vitronectin, concentrations based on prior titering to optimize adhesion of SMCs). After $1 \mathrm{~h}$, nonadherent cells were removed by gentle washing with PBS and attached cells were fixed with ice-cold acetone and stained with Giemsa (Sigma). Cell attachment was measured by counting 10 microscopic ( $\times 40$ objective) fields. Attachment to BSA-coated wells $(1 \mathrm{mg} / \mathrm{ml})$ served as control for background adhesion and each assay was done in triplicate. Cell spreading was studied under similar conditions to that for cell attachment except SMCs were fixed $6 \mathrm{~h}$ after seeding instead of $1 \mathrm{~h}$. A digitized video microscopic image of the fixed cells was then acquired. The borders of 30 cells per condition were traced and cell area was determined using calibrated image analysis software (Jandel Scientific, Corte Madera, CA).

Time-lapse video microscopy. SMC migration was evaluated using time-lapse monitoring with a digital video recording system. Migration was monitored with an inverted microscope (Axiovert S100; Carl Zeiss, Inc., Thornwood, NY) using a $\times 10$ objective and a halogen light source. A CCD video camera (Sony XC-75/75CE) attached to the microscope was used to generate video images which were digitally acquired over a 6-8-h recording period using custom-written time-lapse software. Ambient temperature was maintained at $37^{\circ} \mathrm{C}$ by mounting the culture dish in a temperature control cell (CC-100; 20/20 Technology Inc. Wilmington, NC) and applying a stream of warmed air $\left(37^{\circ} \mathrm{C}\right)$ above the culture lid to prevent condensation. Cells were incubated in bicarbonate-reduced medium (M199 with Hanks' salts and $25 \mathrm{mM}$ Hepes; Life Technologies Inc.) to maintain physiologic $\mathrm{pH}$ in room air. Migration was measured from digital images by tracking the location of cell centroids at hourly intervals. Migration speed was determined as the sum of hourly distances divided by the total time as described previously (37).

Immunofluorescence microscopy. SMCs seeded onto matrixcoated glass slides were fixed in ice-cold acetone and immunostained using previously described methods (38). Bound primary antibody was detected with FITC-labeled anti-rabbit or anti-mouse IgG and visualized using an Olympus BX microscope equipped for fluorescein and Hoescht 33258 fluorescence.

Flow cytometry. Flow cytometry for detection of integrin expression was carried out by indirect immunofluorescence staining as described previously $(39,40)$. Early confluent SMCs were trypsinized and washed in cold PBS with 1\% BSA. Cells were incubated for 30 min on ice with $\mathrm{mAb}$ HB1.1 or isotype-matched control mAb at predetermined saturating concentrations. Washed cells were incubated with FITC-labeled anti-mouse $\mathrm{F}\left(\mathrm{ab}^{\prime}\right)_{2}$ fragment and fluorescence staining was analyzed using a FACScan ${ }^{\circledR}$ (Becton Dickinson, Mountain View, CA).

Statistics. Data are expressed as mean \pm SEM. Comparisons were made by $t$ test or ANOVA with Scheffé's post-hoc test. Statistical significance was set at $P<0.05$. 


\section{Results}

EDHB and DHP inhibit type I collagen production by SMCs. To characterize the effects of EDHB and DHP on collagen production by SMCs, near confluent cells were incubated with inhibitors for $4 \mathrm{~d}$ and the amount of type I collagen secreted into medium over the final $2 \mathrm{~d}$ was evaluated by Western blot analysis. Blots were probed using antiserum LF67. This antiserum recognizes the $\mathrm{C}$-telopeptide triple helical domain of $\alpha 1$ (I) collagen and we have shown previously that on immunoblots it identifies full-length pro- $\alpha 1$ (I) collagen chain, partially processed pro- $\alpha 1(\mathrm{I})$ collagen chains lacking $\mathrm{NH}_{2}$ - or $\mathrm{COOH}-$ terminal propeptides, and mature $\alpha 1(\mathrm{I})$ collagen chain (38). As shown in Fig. 1, both EDHB and DHP induced a concentration-dependent decrease in each of these forms. The concentration range of EDHB over which collagen production was inhibited was similar to that observed in other cell types $(27,41,42)$, and a dose of $400 \mu \mathrm{M}$ EDHB was used for further inhibition studies. DHP was less effective on a molar basis than EDHB in reducing collagen secretion, although it should be noted that DL enantomers of DHP were used of which only the $\mathrm{L}$ form is biologically active. A dose of $1 \mathrm{mM}$ DHP was used for further inhibition studies which is similar to the effective concentration found in other cell types (43). No toxicity with either EDHB or DHP at these concentrations was observed, as evidenced by trypan blue exclusion. A modest decrease in SMC proliferation was observed, consistent with reports using other collagen synthesis inhibitors $(44,45)$, however total protein synthesis per microgram of DNA, determined by $\left[{ }^{3} \mathrm{H}\right]$ leucine incorporation into TCA precipitable material, was unaffected by the inhibitors (data not shown). Because EDHB is an analogue of $\alpha$-ketoglutarate, a component of intermediary metabolism, the effect of the collagen synthesis inhibitors on cellular ATP content was assessed by luciferase assay. ATP content fell in postconfluent SMCs and in SMCs exposed to ATP-depleting agents (antimycin A and

A
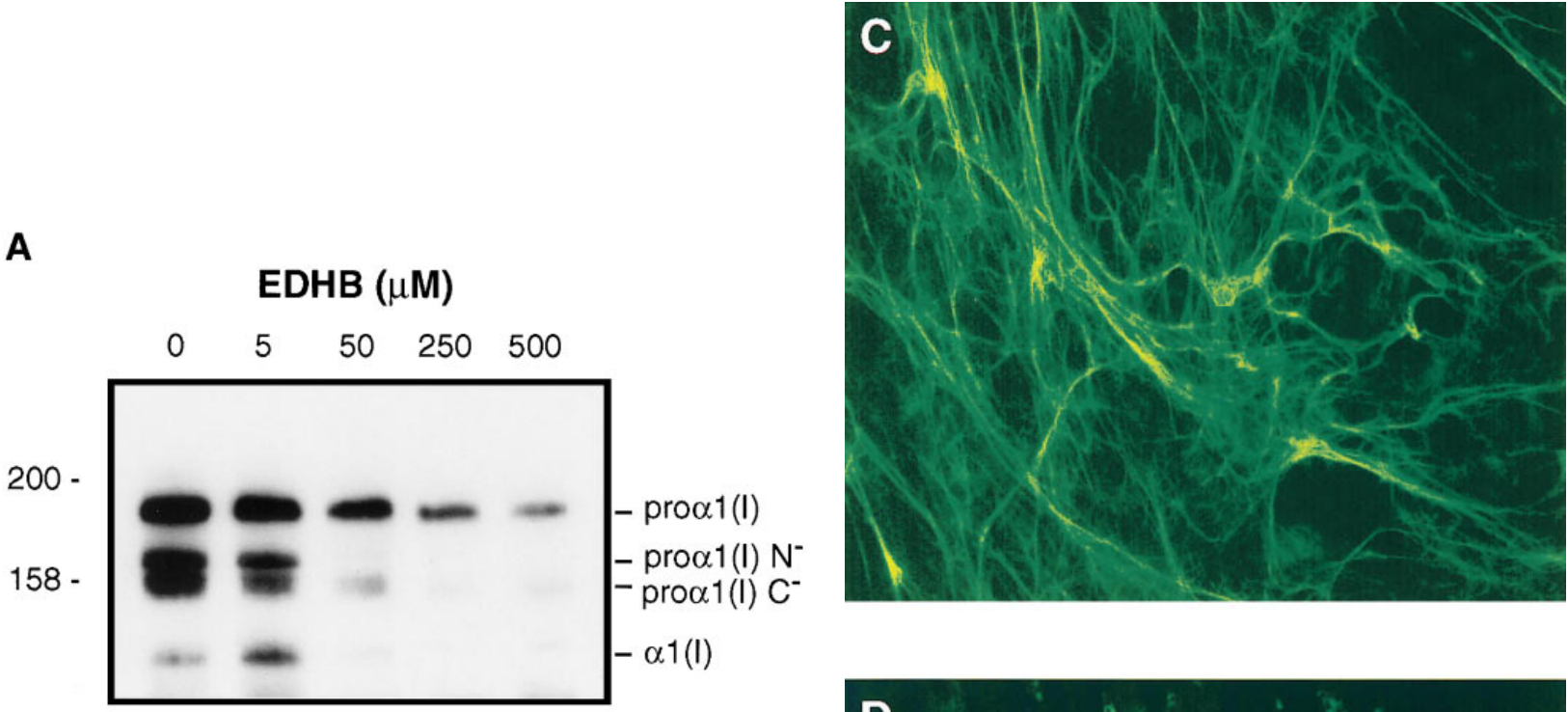

B
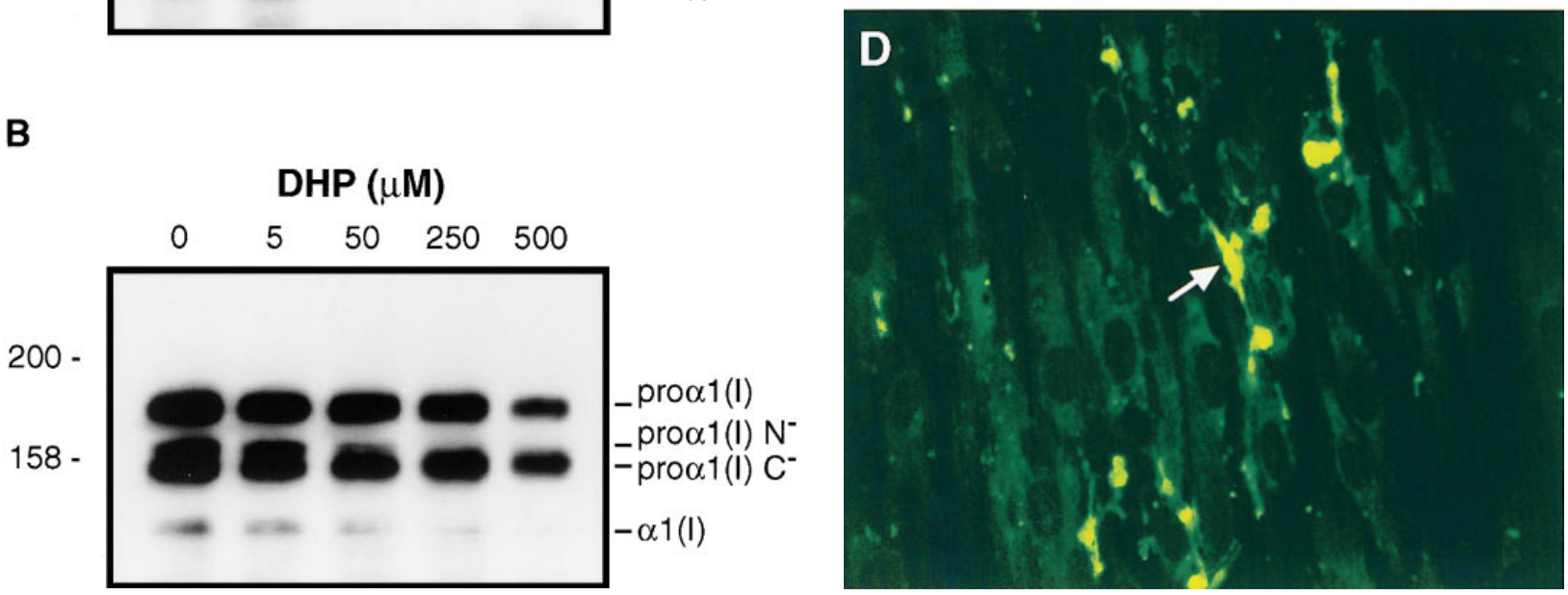

Figure 1. Effect of EDHB and DHP on elaboration of type I collagen by arterial SMCs. $(A$ and $B)$ SMCs were incubated for $4 \mathrm{~d}$ with the designated concentrations of EDHB $(A)$ or DHP $(B)$ and conditioned media from the final $48 \mathrm{~h}$ of incubation were subjected to Western blot analysis. Bands detected by the antibody LF67 include pro- $\alpha 1(\mathrm{I})$ collagen chain, partially processed pro- $\alpha 1(\mathrm{I})$ collagen chain lacking either the $\mathrm{NH}_{2^{-}}$ or COOH-terminal propeptides, and fully processed $\alpha 1(\mathrm{I})$ collagen chain (38). The level of each species is reduced by the inhibitors. (C and $D$ ) Immunofluorescence micrographs of 10-d SMC cultures under control conditions $(C)$ and cultures incubated for the final $4 \mathrm{~d}$ with $400 \mu \mathrm{M}$ $\operatorname{EDHB}(D)$. Formation of an extracellular collagen fiber network is inhibited by EDHB and only amorphous, focal accumulations of immunoreactive collagen is evident (arrow). 
2-deoxy D-glucose) but there was no detectable reduction in ATP content of SMCs incubated for 3-4 d with EDHB or DHP (data not shown).

To determine the effect of the inhibitors on elaboration of an insoluble collagen fiber matrix, SMC cultures were immunostained using LF67. This revealed a marked reduction in the formation of an insoluble collagen fiber matrix. Fig. $1 C$ illustrates the elaborate collagen fiber network detectable in control cultures after 10 d. Fig. $1 D$ illustrates the findings observed in 10-d cultures when SMCs were exposed to EDHB $(400 \mu \mathrm{M})$ for the final $4 \mathrm{~d}$. Here, only sparse extracellular immunoreactivity was evident which had an amorphous, nonfibrillar appearance, consistent with abnormal fibrillogenesis of underhydroxylated collagen or accelerated degradation of abnormal fibers (Fig. $1 \mathrm{D}$, arrow) (46).

$S M C$ spreading but not attachment is inhibited by EDHB and DHP. To determine the effect of the inhibitors on SMC attachment, SMCs were treated with collagen synthesis inhibitors for $4 \mathrm{~d}$, trypsinized, and seeded onto a given matrix protein. Under control (untreated) conditions, the percentage of total cells added that attached to type I collagen and vitronectin was $76 \pm 9$ and $80 \pm 10 \%$, respectively. As shown in Fig. $2 A$, prior treatment of SMCs with inhibitors did not affect cell attachment to either of these substrates. Attachment to type IV collagen, type $\mathrm{V}$ collagen, and fibronectin was also unaffected by the inhibitors (data not shown).

We next determined the effect of inhibitors on the ability of SMCs to spread over a preformed collagen substrate, by quantifying SMC area $6 \mathrm{~h}$ after seeding. As shown in Fig. $2 \mathrm{~B}$, SMCs pretreated with either EDHB or DHP spread on type I collagen substantially less than did vehicle-treated cells $(P<$ 0.01). Impaired spreading was also observed when SMCs were seeded on type III collagen, type IV collagen, and type V collagen (data not shown). Addition of $20 \mu \mathrm{g} / \mathrm{ml}$ ascorbate to EDHP-treated SMCs partially reversed the abnormality in spreading ( $40 \%$ restoration of the response, $P<0.05$ ); higher doses of ascorbate were associated with cell toxicity (data not shown). In contrast to the substantially impaired spreading on collagen substrates, EDHB and DHP had no significant effect on SMC spreading on vitronectin (Fig. $2 B$ ).

$E D H B$ and DHP inhibit SMC locomotion and migration speed. To evaluate the effect of EDHB and DHP on SMC movement, digital time-lapse video microscopy was used. This was performed initially with cells seeded on uncoated substrates and allowed to grow for $4 \mathrm{~d}$ in the absence of inhibitors to permit endogenous formation of a primordial ECM. EDHB, DHP, or vehicle was then added for a further $4 \mathrm{~d}$ and the migration path of individual cells was tracked over $7 \mathrm{~h}$. The migration speed for each cell was also determined. Migration was also studied 2-3 d after washout of the respective inhibitor. Representative migration paths shown in Fig. 3 illustrate a striking decrease in motility of SMCs after exposure to either EDHB or DHP. This effect was fully reversible upon washout of the inhibitor. The mean migration speed of SMCs treated with EDHB was reduced by $42 \%(P<0.05)$ and the speed of SMCs treated with DHP was reduced by $45 \%(P<0.05)$. Mean cell migration speed in both instances returned to control levels 2-3 d after removal of the inhibitor. An apparent trend toward suprabasal migration speeds after washout of the inhibitors was not statistically significant.

We then determined if the antimigratory effect of the collagen synthesis inhibitors was influenced by specific exogenous
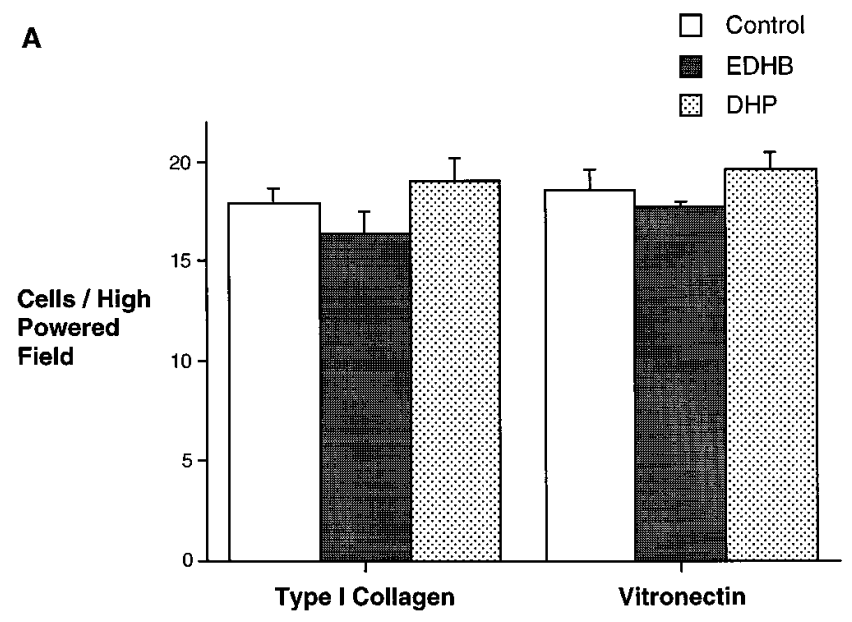

B

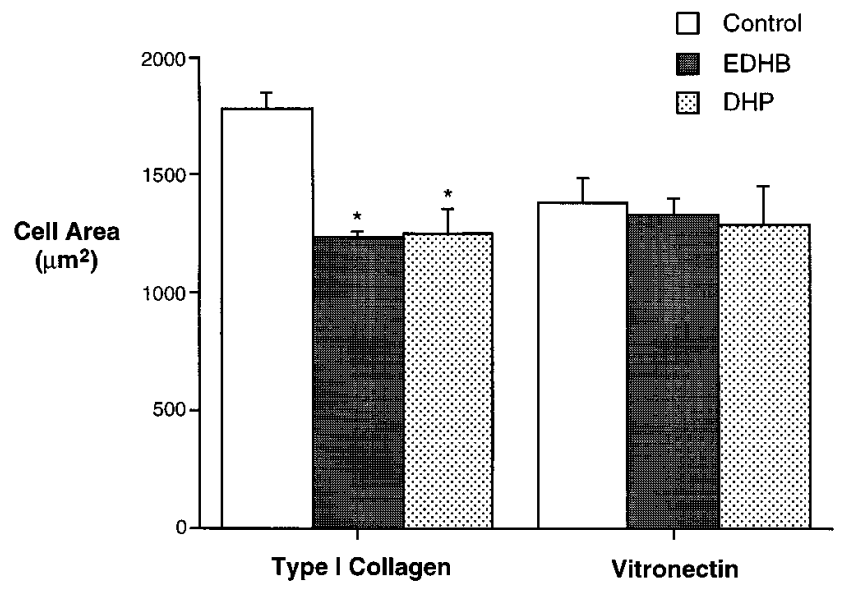

Figure 2. Effect of inhibiting collagen synthesis on SMC attachment and spreading. ( $A$ ) SMCs, incubated for $4 \mathrm{~d}$ with or without EDHB $(400 \mu \mathrm{M})$ or DHP $(1 \mathrm{mM})$, were seeded onto matrix-coated glass coverslips and attachment after $1 \mathrm{~h}$ was determined as described in Methods. No effect of the inhibitors on attachment to type I collagen or vitronectin was observed. (B) SMC spreading was determined $6 \mathrm{~h}$ after seeding cells on the designated substrate by tracing cell borders of a digitized image. $* P<0.01$ vs. control.

ECM constituents. SMCs were treated with inhibitors for $30 \mathrm{~h}$, detached with trypsin-EDTA, and reseeded onto substrates precoated with type I collagen $(15 \mu \mathrm{g} / \mathrm{ml})$, fibronectin $(15$ $\mu \mathrm{g} / \mathrm{ml})$, or vitronectin $(1 \mu \mathrm{g} / \mathrm{ml})$. Cells were allowed to attach and spread for a further $24 \mathrm{~h}$ in the presence of the respective inhibitor and single cell migration was assessed as described above. As illustrated in Fig. 3 I, treatment with EDHB or DHP decreased migration speed on collagen by $42 \%(P<0.01)$ and $33 \%(P<0.05)$, respectively; on fibronectin by $50 \%(P<$ $0.01)$ and $33 \%(P<0.05)$, respectively; and on vitronectin by $32 \%(P<0.05)$ and $21 \%(P<0.05)$, respectively.

$\beta 1$ integrin clustering and focal adhesion complex formation is inhibited by $E D H B$ and DHP. Collagen interacts with SMCs through $\beta 1$ integrins and this interaction can mediate adhesion, migration, and ECM signaling (47-49). When not engaged by ligand, integrins exist diffusely on the cell surface 

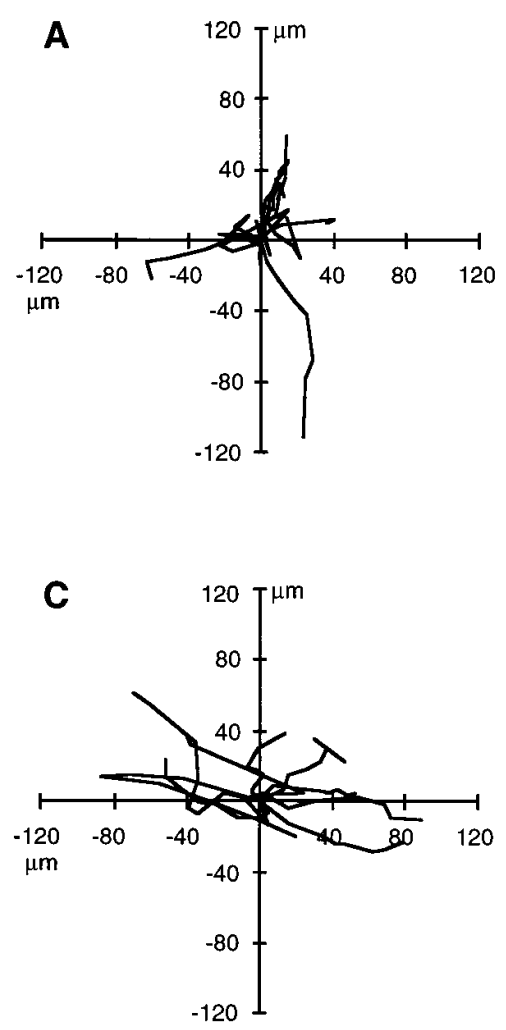
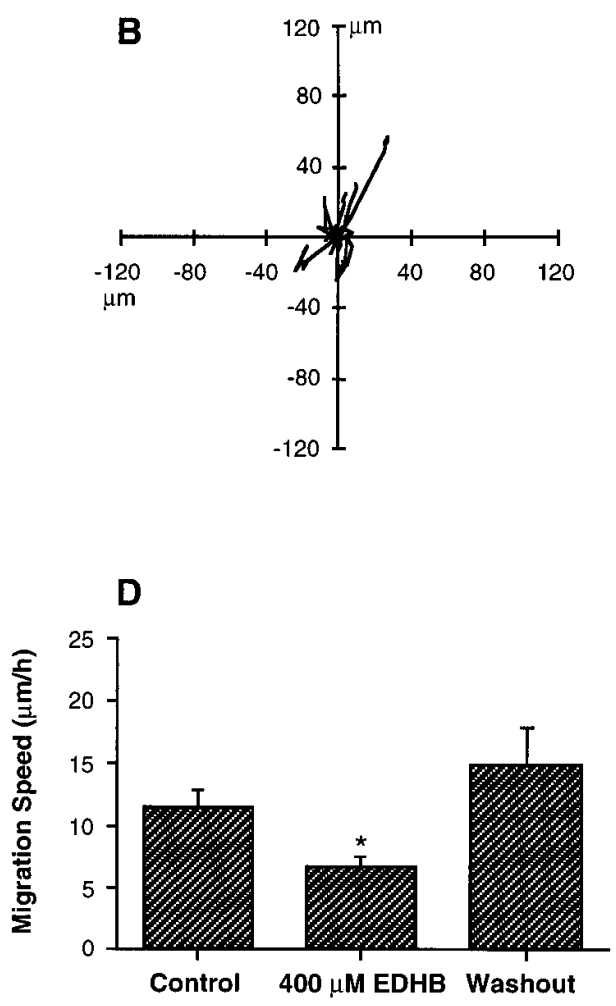

Figure 3. Effect of inhibiting collagen synthesis on SMC migration path $(A-C, E-G)$ and migration speed ( $D$ and $H$ ) as monitored by digital time-lapse video microscopy. Migration paths depict hourly translocations of 10 cells per experimental condition, over a period of $7 \mathrm{~h}$. (A) Control SMCs. (B) SMCs treated for $4 \mathrm{~d}$ with $400 \mu \mathrm{M}$ EDHB. (C) EDHB-treated SMCs shown in $B, 2 \mathrm{~d}$ after removal of the inhibitor. $(D)$ Mean migration speed of the SMCs depicted in $A-C$. (E) Control SMCs for $F$ and $G$. $(F)$ SMCs treated for $4 \mathrm{~d}$ with $1 \mathrm{mM}$ DHP. ( $G$ ) DHP-treated SMCs shown in $F, 3 \mathrm{~d}$ after removal of the inhibitor. $(H)$ Mean migration speed of SMCs depicted in $E-G$. (I) Migration speed of control and treated SMCs migrating on type I collagen, fibronectin, and vitronectin. ${ }^{*} P<0.05$ vs. untreated SMCs; ${ }^{\dagger} P<$ 0.01 vs. untreated SMCs. but upon ligand binding they aggregate into clusters (50), a process central to integrin-mediated function (51). To examine whether de novo collagen synthesis is required for integrin clustering, SMCs were treated for $4 \mathrm{~d}$ with $\mathrm{EDHB}(400 \mu \mathrm{m})$ or DHP (1 mM) and added to type I collagen-coated glass coverslips in serum-free conditions. Cells were allowed to spread over $6 \mathrm{~h}$, after which they were fixed and stained with $\mathrm{mAb}$ HB1.1, an anti- $\beta 1$ antibody. In control SMCs, $\beta 1$ integrins distributed into adhesion complexes beneath the cell body and at the cell periphery (Fig. 4). However, in cells treated with collagen inhibitors, $\beta 1$ integrin complexes were poorly visualized and at best rudimentary. Importantly, neither EDHB nor DHP inhibited the total surface expression of $\beta 1$ integrins on SMCs as measured by flow cytometry (Fig. 4, bottom), implicating a selective defect in integrin aggregation. In agreement with the quantitative data on cell spreading (Fig. 2 B), treated cells were poorly spread and often assumed atypical shapes.

Ligation and clustering of integrins occurs in concert with recruitment of cytoskeletal proteins into focal adhesion complexes on the inner face of the cell membrane (for review see reference 52). To visualize focal complex assembly, spreading cells were immunostained for vinculin. As shown in Fig. 5, vinculin-containing focal adhesion complexes were clearly evident in control cells seeded on collagen, both 1 and $6 \mathrm{~h}$ after seeding. In contrast, in SMCs preincubated with collagen synthesis inhibitors, focal adhesions were much less apparent. In some cells, a dispersed accumulation of vinculin was apparent at the edge of atypical cell extensions (Fig. $5 C$, arrow), suggesting a failed or retarded attempt at focal contact assembly.

EDHB and DHP induce disassembly of the actin cytoskeleton. Several focal adhesion proteins, including vinculin, are capable of binding actin (53) and this linkage to the actin cy- toskeleton is critical for cell motility (54). To determine the effect of collagen synthesis inhibitors on actin organization, SMCs were immunostained for smooth muscle $\alpha$-actin. As shown in Fig. 6 collagen synthesis inhibitors led to nearly complete loss of smooth muscle $\alpha$-actin-containing stress fibers after $4 \mathrm{~d}$ of incubation. Western blot analysis for smooth muscle $\alpha$-actin monomers demonstrated that actin expression was unaffected by the inhibitors (Fig. $6 C$ ), implying that the loss of fiber staining was due to microfilament disassembly (or lack of assembly) rather than an effect on smooth muscle $\alpha$-actin expression.

\section{Discussion}

To investigate a functional linkage between SMC motility and collagen synthesis, we exploited the physiologic requirement of prolyl-4-hydroxylase in the production of collagen. The cotranslational hydroxylation of proline is known to play a critical role in stabilizing the triple helix in the collagen molecule. When proline hydroxylation is inhibited, cells continue to make pro- $\alpha$ chains, but these chains remain in an unstructured, nonhelical conformation. The resultant molecule can be secreted from the cell as a nonfunctioning protein but most of it accumulates intracellularly within the endoplasmic reticulum (46). The two inhibitors used in the current study, EDHB and DHP, have both been shown to reduce proline hydroxylation and collagen production; however, they do so through distinct actions. EDHB is a structural analogue of ascorbate and $\alpha$-ketoglutarate, two essential cofactors for prolyl-4-hydroxylase. DHP does not directly inhibit prolyl-4-hydroxylase but instead incorporates into pro- $\alpha$ chains where, unlike proline, it does not become hydroxylated. Both reagents were found to inhibit 

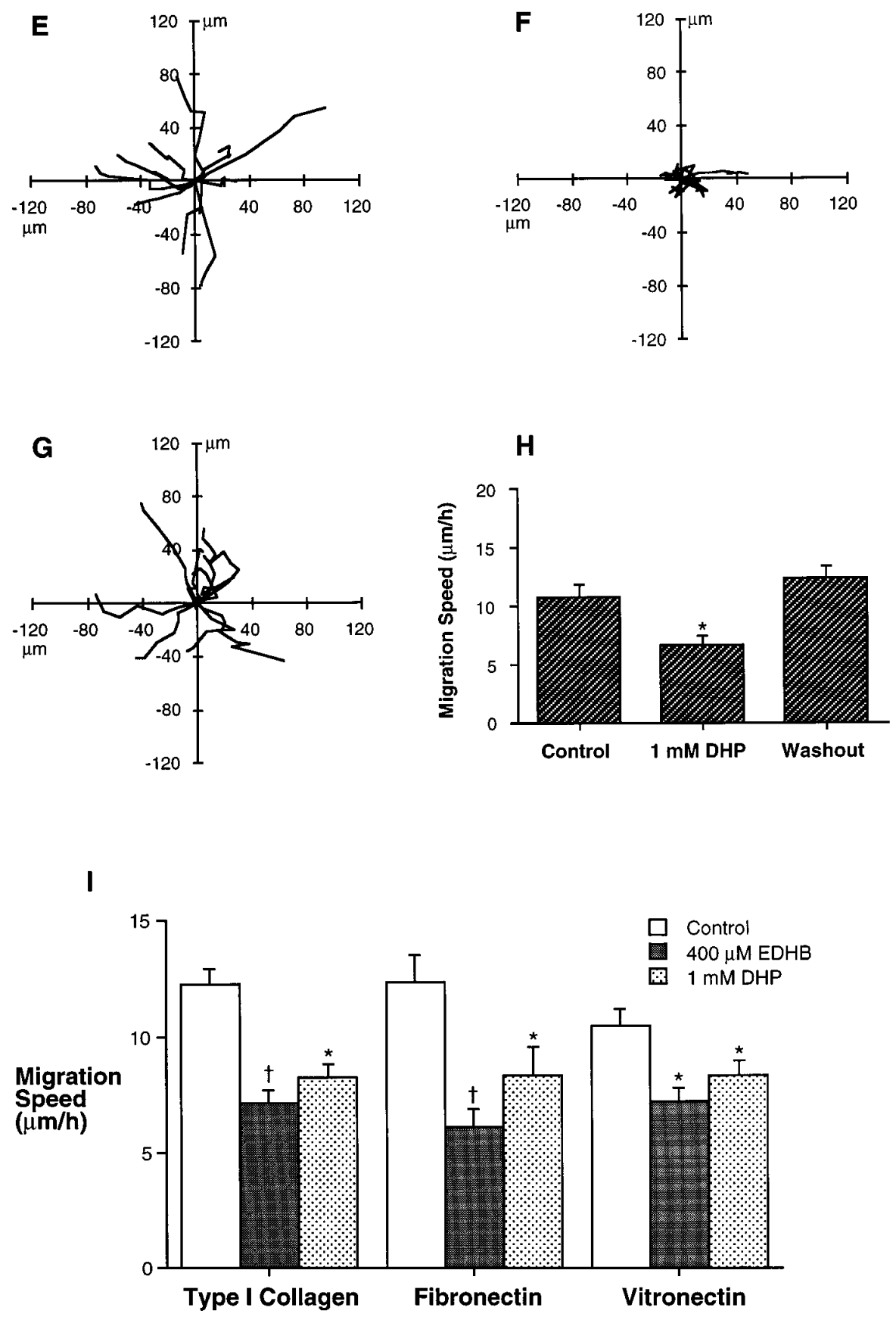

Figure 3 (Continued)

production of type I collagen by SMCs in a dose-dependent fashion: there was a decline in the amount of collagen secreted into the culture medium and a striking decrease in the amount of collagen deposited on the culture substrate.

Several lines of evidence indicate that the inhibitors used were not toxic to SMCs and that the effect on collagen production was specific: $(a)$ trypan blue exclusion was unaffected by the inhibitors; $(b)$ there was no effect of inhibitors on SMC attachment to an ECM substrate; (c) the effect of EDHB and DHP on SMC migration was fully reversible upon washout of the reagents; (d) SMC total protein synthesis, as measured by incorporation of $\left[{ }^{3} \mathrm{H}\right]$ leucine, was unaffected by the inhibitors; (e) there was no effect of inhibitors on the expression of either smooth muscle $\alpha$-actin or of $\beta 1$ integrins, as assessed by West- ern blot analysis and flow cytometry, respectively; $(f)$ addition of $20 \mu \mathrm{g} / \mathrm{ml}$ ascorbate partially overcame the effects of EDHB; and $(g)$ cellular ATP levels did not fall in response to either EDHB or DHP. In addition to these data, previous studies with proline hydroxylation inhibitors have shown that elastin secretion is unaffected $(55,56)$.

What is the mechanism by which the collagen synthesis inhibitors retarded SMC spreading and migration? It has been shown previously that the integrity of the ECM-cytoskeletal linkage is critical for force generation and directed movement of the cell membrane (48). We propose that the collagen synthesis inhibitors prevented efficient shape change and migration of SMCs by disrupting this linkage. Specifically, by failing to elaborate a primordial collagen fiber substrate, SMCs were 
Control
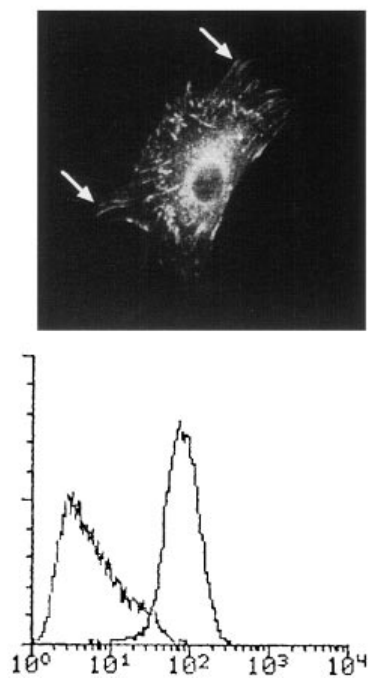

EDHB
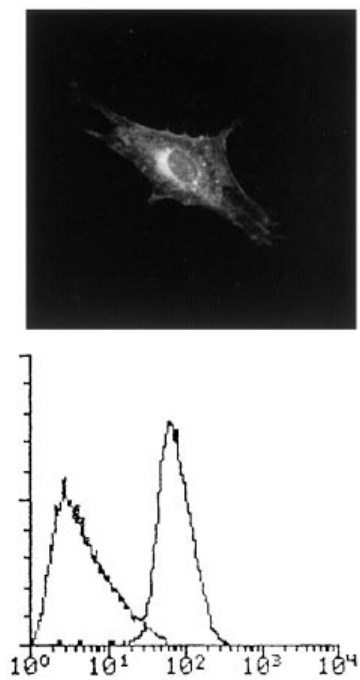

DHP
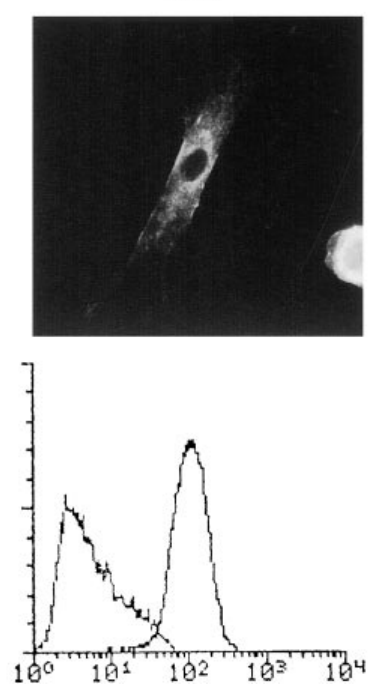

Figure 4. Effect of collagen synthesis inhibitors on localization and expression of $\beta 1$ integrins in arterial SMCs. (Top) Immunofluorescence photomicrographs of control SMCs and cells exposed to collagen synthesis inhibitors. Untreated SMCs and SMCs treated for $4 \mathrm{~d}$ with either EDHB or DHP were released from cultures with trypsin-EDTA, seeded onto type I collagen-coated glass coverslips, and fixed and immunostained for $\beta 1$ integrins using $\mathrm{mAb}$ HB1. 1 after 6 h. Arrows depict $\beta 1$ integrin clusters at the periphery of a spreading, untreated SMC. (Bottom) Flow cytometry analysis using the same antiintegrin antibody showing no effect of collagen synthesis inhibitors on total surface expression of $\beta 1$ integrins. The tracing on the left of each histogram depicts background signal of the isotype-matched control antibody. unable to optimally interact with the ECM to generate the traction and force required for normal movement. This interpretation is supported by the observation that $\beta 1$ integrin aggregation was impaired by the inhibitors. Clustering of integrins is dependent on integrin binding to a multivalent ECM ligand $(57,58)$. By preventing the elaboration of suitable adhesive ligand, the inhibitors may have abrogated, or at least impaired, this clustering reaction. The observed abnormality in focal contact formation, studied by staining for vinculin, is consistent with this view, recognizing that recruitment of focal adhesion proteins into focal contacts is dependent on integrin occupancy by ligand and integrin clustering (51). Finally, disruption of smooth muscle $\alpha$-actin-containing microfilament bundles by the inhibitors also supports this paradigm. Focal adhesions are the major sites of attachment of actin stress fibers to the cell surface. The loss of actin stress fibers, in the ab- sence of any decrease in expression of the monomeric $G$ forms, suggests that the fibers disassembled in response to losing contact with the focal adhesion proteins to which they are normally anchored. Taken together, the findings suggest that the lack of newly elaborated collagen in the immediate vicinity of the SMC prevented the normal chain of transmembrane linkages required for motility.

It remains possible that effects of EDHB and DHP other than decreased collagen secretion may have altered the migratory behavior of cells. For example, substitution of DHP for proline in noncollagenous proteins might alter conformation and function of such proteins. However, the observation that two mechanistically distinct collagen synthesis inhibitors yielded similar effects in all endpoints studied strongly supports the notion that the decrease in SMC motility, as well as in integrin and cytoskeleton organization, was a consequence of inhibited

\section{Control}

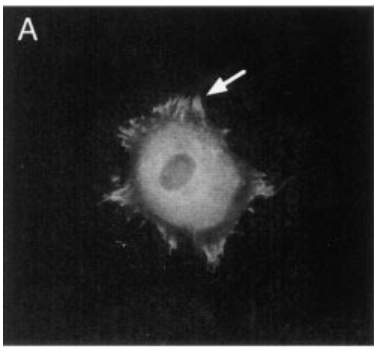

D

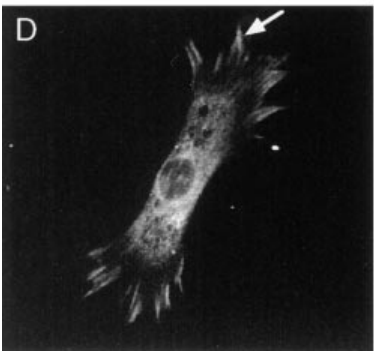

EDHB
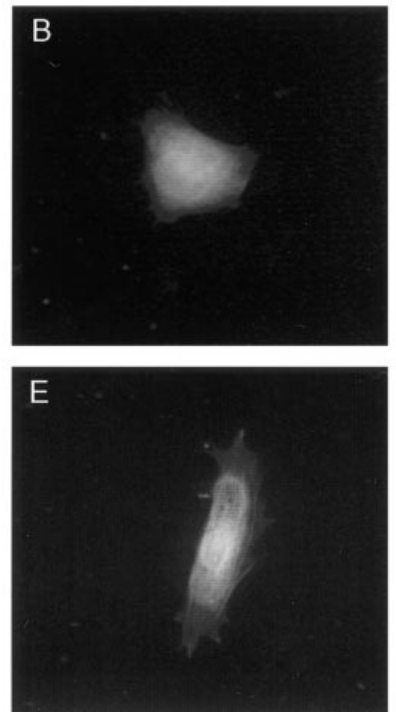

DHP
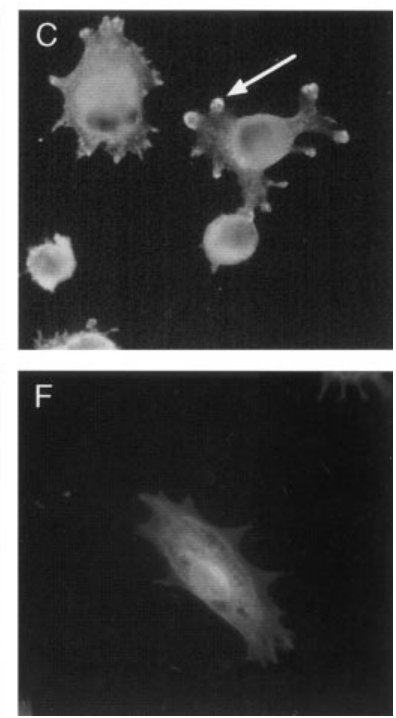

Figure 5. Immunofluorescence photomicrographs showing the effect of collagen synthesis inhibitors on focal contact assembly in spreading SMCs. SMCs treated with or without collagen synthesis inhibitors for $4 \mathrm{~d}$ were seeded onto type I collagen and immunostained for vinculin after $1 \mathrm{~h}(t o p)$ or $6 \mathrm{~h}$ (bottom). Vinculin-containing focal adhesion contacts are evident in the periphery of control cells ( $A$ and $D$, short arrows) but are absent or atypical $(C$, long arrow) in cells treated with $400 \mu \mathrm{M}$ EDHB $(B$ and $E$ ) or $1 \mathrm{mM} \mathrm{DHP}(C$ and $F)$. 

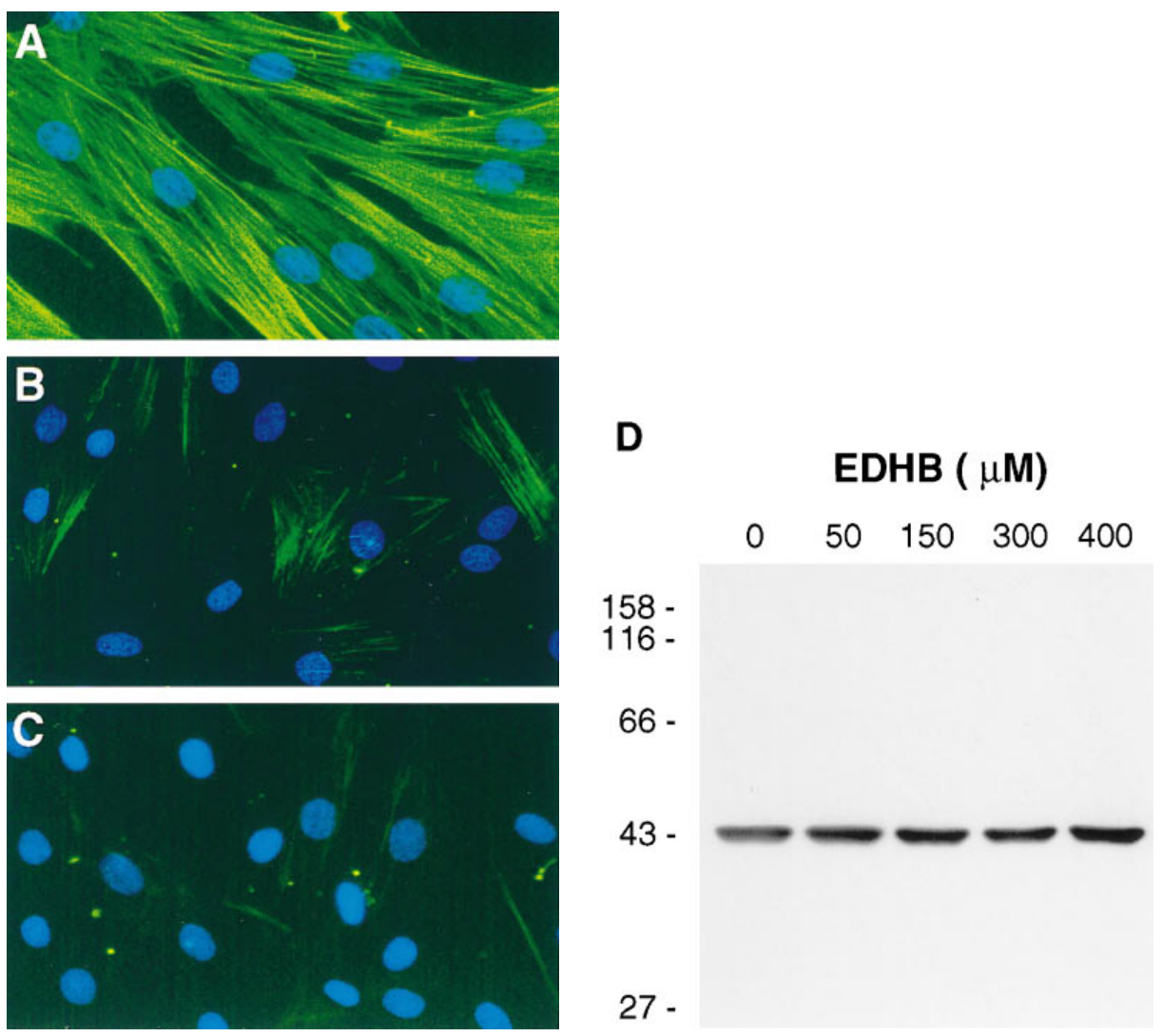

Figure 6. Effect of inhibiting collagen synthesis on smooth muscle $\alpha$-actin organization. $(A-C)$ Fluorescence photomicrographs of control SMCs $(A)$, SMCs incubated for $2 \mathrm{~d}$ with $400 \mu \mathrm{m}$ $\operatorname{EDHB}(B)$, and SMCs incubated for $4 \mathrm{~d}$ with $400 \mu \mathrm{m} \operatorname{EDHB}(C)$ and immunostained for smooth muscle $\alpha$-actin. Nuclei are stained with Hoechst 33258. (D) Western blot of cell lysates of SMCs incubated for $4 \mathrm{~d}$ with EDHB. Cellular proteins were resolved on a $15 \%$ polyacrylamide gel and transferred proteins were immunodetected using smooth muscle $\alpha$-actin-specific $\mathrm{mAb}$ (clone 1A4). Despite inducing a loss of stress fibers, EDHB had no effect on cellular abundance of monomeric smooth muscle $\alpha$-actin.

collagen production. We also cannot discount the possibility that the effect of the inhibitors on spreading and migration was partly a consequence of intracellular accumulation of abnormal collagen. However, the observation that SMCs incubated with EDHB and DHP spread normally on vitronectin suggests that the effect was primarily an extracellular one and that the spreading impairment could be overcome by an ECM environment that supplied other adhesive ligands, such as vitronectin, that could be efficiently harnessed by the cell.

The inhibitory effects of EDHB and DHP on SMC spreading were observed for cells seeded on collagen-coated substrates, including collagen types I, III, IV, and V. Similarly, SMC migration on collagen remained impaired. The failure of exogenous collagen to support normal spreading or migration of cells treated with collagen synthesis inhibitors is consistent with previous studies of epithelial cell outgrowth from mouse skin explants (59) and implies a functional difference between newly elaborated collagen and preformed, exogenous collagen. One possibility is that a specific collagen other than those tested may be essential for SMC spreading and motility, and would have corrected the abnormality if it were added. Type VIII collagen has been shown recently to be expressed by rat SMCs after balloon injury $(22,60)$ and is a candidate in this regard. However, it is also recognized that purified preformed collagens do not mimic the ECM environment that develops de novo either in vitro or in vivo as they differ in fiber size, fiber organization, and degree of polymerization. It is thus unlikely that the biochemical and structural features of newly and continually elaborated collagen are similar to those of a preexisting collagen fiber matrix. Our results suggest that
SMC attachment to a preformed fiber lattice is not dependent on the production of new collagen; however, SMC spreading and migration are dependent on this additional response. That is, the preformed lattice was not sufficient to mediate the dynamic cell surface rearrangements required for cell spreading and migration and concomitant deposition of newly synthesized collagen was required.

It is noteworthy that the collagen synthesis inhibitors impaired migration not only on a collagen substrate but also on fibronectin and vitronectin. Thus, elaboration of new collagen may be important for SMC motility in a variety of ECM environments. It is well established that both fibronectin and vitronectin bind collagen fibers and appropriate interaction with nascent collagen may optimize ECM assembly and organization, which in turn could affect migration $(61,62)$. Of note, even though spreading of SMCs on vitronectin was not influenced by the inhibitors, migration was inhibited. This may reflect the fact that migration is a more complex phenomenon than spreading, and that whereas $\alpha \mathrm{v}$ integrin-based interaction with vitronectin may be sufficient for normal spreading on this substrate, additional elaboration of nascent collagen is necessary to facilitate the coordinated and sustained movement patterns required for migration on this and other substrates.

The role of de novo synthesized collagen in cell motility might be similar to that previously described for fibronectin. Fibronectin matrices can be endowed with positional information that contributes to directional migration and have been shown to provide migratory tracks for mesoderm cells during development $(63,64)$. Early collagen matrices might also act as migratory paths for motile cells, either alone or through their 
interaction with other ECM constituents. In this regard it is noteworthy that the migration speed of SMCs preincubated with inhibitors was reduced by $\sim 40 \%$, while the effect on migration path was even more striking. Motion analysis of individual SMCs revealed small oscillatory-like changes in centroid location, with minimal persistent movement away from the cell's point of origin (e.g., Fig. $3 F$ ), consistent with the absence of a structural path for crawling.

In summary, we have demonstrated that SMCs require de novo production of collagen to sustain normal migration in vitro. We propose that this biosynthetic response is necessary to ensure that the collagenous ECM is appropriately structured to maintain the transcellular traction system required for locomotion. Recent studies have established that deposition of new collagen is an early response to vascular injury (20-22, $65)$. The current studies suggest that this response may be important for facilitating SMC migration during the remodeling process. Inhibition of collagen synthesis may thus be a novel approach to controlling SMC migration during pathologic arterial restructuring.

\section{Acknowledgments}

The authors thank Dr. C.G. Ellis for assistance with the ATP assay and Dr. L.H. Chow for critical appraisal of the manuscript.

This research was supported by grants from the Medical Research Council of Canada (MT11715) and Heart and Stroke Foundation of Canada (T3485). J.G. Pickering and B.M.C. Chan are supported by MRC Scholarships. E. Rocnik was supported by the London Health Sciences Centre Internal Research Fund.

\section{References}

1. Ross, R. 1993. The pathogenesis of atherosclerosis: a perspective for the 1990s. Nature. 362:801-809.

2. Casscells, W. 1992. Endothelial and smooth muscle cell migration: critical factors in restenosis. Circulation. 86:723-729.

3. Libby, P. 1995. Molecular basis of acute coronary syndromes. Circulation. 91:2844-2850.

4. Ferns, G.A.A., E.W. Raines, K. Sprugel, A.S. Motani, M.A. Reidy, and R. Ross. 1991. Inhibition of neointimal smooth muscle accumulation after angioplasty by an antibody to PDGF. Science. 253:1129-1132.

5. Grotendorst, C.R., T. Chang, H.E.J. Seppa, H.K. Kleinman, and G.R. Martin. 1982. Platelet-derived growth factor is a chemoattractant for vascular smooth muscle cells. J. Cell. Physiol. 113:261-266.

6. Pickering, J.G., S. Uniyal, C. Ford, T. Chau, M.A. Laurin, L.H. Chow, C.G. Ellis, J. Fish, and B.M.C. Chan. 1997. Fibroblast growth factor-2 potentiates vascular smooth muscle cell migration to platelet-derived growth factor: upregulation of $\alpha 2 \beta 1$ integrin and disassembly of actin filaments. Circ. Res. 80: 627-637.

7. Bilato, C., R.R. Pauly, G. Melillo, R. Monticone, D. Gorelick-Feldman, Y. Gluzband, S.S. Sollott, B. Ziman, E.G. Lakatta, and M.T. Crow. 1995. Intracellular signaling pathways required for rat vascular smooth muscle cell migration. Interaction between basic fibroblast growth factor and platelet-derived growth factor. J. Clin. Invest. 96:1905-1915.

8. Koyama, N., T. Koshikawa, N. Morisaki, Y. Saito, and S. Yoshida. 1990. Bifunctional effects of transforming growth factor- $\beta$ on migration of cultured rat aortic smooth muscle cells. Biochem. Biophys. Res. Commun. 169:725-729.

9. Bell, L., and J.A. Madri. 1989. Effect of platelet factors on migration of cultured bovine aortic endothelial and smooth muscle cells. Circ. Res. 65:10571065 .

10. Naito, M., T. Hayashi, M. Kuzua, C. Funaki, K. Asai, and F. Kuzuya. 1990. Effects of fibrinogen and fibrin on the migration of vascular smooth muscle cells in vitro. Atherosclerosis. 83:9-14.

11. Boudreau, N., E. Turley, and M. Rabinovitch. 1991. Fibronectin, hyaluronan, and a hyaluronan binding protein contribute to increased ductus arteriosus smooth muscle cell migration. Dev. Biol. 143:235-247.

12. Savani, R.C., C. Wang, B. Yang, S. Zhang, M.G. Kinsella, T.N. Wight, R. Stern, D.M. Nance, and E.A. Turley. 1995. Migration of bovine aortic smooth muscle cells after wounding injury. The role of hyaluronan and RHAMM. J. Clin. Invest. 95:1158-1168. 65-97.

13. Barnes, M.J. 1985. Collagens in atherosclerosis. Collagen Relat. Res. 5

14. Shekhonin, B.V., S.P. Domagatsky, V.R. Muzykantof, G.Y. Idelson, and V.S. Rukosuev. 1985. Distribution of type I, III, IV and V collagen in normal and atherosclerotic human arterial wall. Immunomorphologic characteristics. Collagen Relat Res. 5:355-368.

15. Shekhonin, B.V., S.P. Domagatsky, G.L. Idelson, V.E. Koteliansky, and V.S. Rukosuev. 1987. Relative distribution of fibronectin and type I, III, IV, and $\mathrm{V}$ collagens in normal and atherosclerotic intima of human arteries. Atherosclerosis. 67:9-17.

16. Pickering, J.G., C. Ford, and L.H. Chow. 1996. Evidence for rapid accumulation and persistently disordered architecture of fibrillar collagen in human restenosis lesions. Am. J. Cardiol. 78:633-637.

17. Reissen, R., J.M. Isner, E. Blessing, C. Loushin, S. Nikol, and T.N. Wight. 1994. Regional differences in the distribution of biglycan and decorin in the extracellular matrix of atherosclerotic and restenotic human coronary arteries. Am. J. Pathol. 144:962-974.

18. Skinner, M.P., E.W. Raines, and R. Ross. 1994. Dynamic expression of $\alpha 1 \beta 1$ and $\alpha 2 \beta 2$ integrin receptors by human vascular smooth muscle cells. $\alpha 2 \beta 1$ integrin is required for chemotaxis across type I collagen coated membranes. Am. J. Pathol. 145:1070-1081.

19. Petzelbauer, E., J.P. Springhorn, A.M. Tucker, and J.A. Madri. 1996. Role of plasminogen activator inhibitor in the reciprocal regulation of bovine aortic endothelial and smooth muscle cell migration. Am. J. Pathol. 149:923-931.

20. Strauss, B.H., R.J. Chisholm, F.W. Keeley, A.I. Gotlieb, R.A. Logan, and P.W. Armstrong. 1994. Extracellular matrix remodeling after balloon angioplasty injury in a rabbit model of restenosis. Circ. Res. 75:650-658.

21. Majesky, M.W., V. Lindner, D.R. Twardzik, S.N. Schwartz, and M.A. Reidy. 1991. Production of transforming growth factor $\beta 1$ during repair of arterial injury. J. Clin. Invest. 88:904-910.

22. Bendeck, M.P., S. Regenass, W.D. Tom, C.M. Gichelli, S.M. Schwartz, C. Hart, and M.A. Reidy. 1996. Differential expression of $\alpha 1$ type VIII collagen in injured platelet-derived growth factor-BB-stimulated rat carotid arteries. Circ. Res. 79:524-531.

23. Clowes, A., M. Reidy, and M. Clowes. 1983. Kinetics of cellular proliferation after arterial injury. I. Smooth muscle growth in the absence of endothelium. Lab. Invest. 49:327-333.

24. Clowes, A.W., and S.M. Schwartz. 1985. Significance of quiescent smooth muscle cell migration in the injured rat carotid artery. Circ. Res. 56:139-145.

25. Franklin, T.J., N.J. Hales, D. Johnstone, W.B. Morris, C.J. Cunliffe, A.J. Millest, and G.B. Hill. 1991. Approaches to the design of antifibrotic drugs. Biochem. Soc. Trans. 19:812-815.

26. Kivirikko, K.I., R. Myllylä, and T. Pihlajaniema. 1989. Protein hydroxylation: prolyl 4-hydroxylase, an enzyme with four cosubstrates and a multifunctional subunit. FASEB J. 3:1609-1617.

27. Sasaki, T., K. Majamaa, and J. Uitto. 1987. Reduction of collagen production in keloid fibroblast cultures by ethyl-3,4-dihydroxybenzoate. Inhibition of prolyl hydroxylase as a mechanism of action. J. Biol. Chem. 19:9397-9403.

28. Majamaa, K., V. Günzler, H.M. Hanauske-Abel, R. Myllylä, and K.I. Kivirikko. 1986. Partial identity of the 2-oxoglutarate and ascorbate binding sites of prolyl 4-hydroxylase. J. Biol. Chem. 261:7819-7823.

29. Tan, E.M.L., L. Ryhanen, and J. Uitto. 1983. Proline analogues inhibit human skin fibroblast growth and collagen production in culture. J. Invest. Dermatol. 80:261-267.

30. Uitto, J., and D.J. Prockop. 1974. Incorporation of proline analogs into collagen polypeptides. Effect on the production of extracellular procollagen and on the stability of the triple helical structure of the molecule. Biochim. Biophys. Acta. 336:234-251.

31. Fisher, L.W., J. Stubbs, and M.F. Young. 1995. Antisera and cDNA probes to human and certain animal bone matrix noncollagenous proteins. Acta Orthop. Scand. 66(Suppl. 266):61-65.

32. Fleischmajer, R., E.D. MacDonals, J. Perlisch, R.E. Burgeson, and L.W. Fisher. 1990. Dermal collagen fibrils are hybrids of type I and type III collagen molecules. J. Struct. Biol. 105:162-169.

33. Bell, E., B. Ivarsson, and C. Merrill. 1979. Production of a tissue-like structure by contraction of collagen lattices by human fibroblasts of different proliferative potential in vitro. Proc. Natl. Acad. Sci. USA. 76:1274-1278.

34. Ruoslahti, E., E.G. Hayman, M. Pierschbacher, and E. Engvall. 1982. Fibronectin: purification, immunohistochemical properties, and biological activities. Methods Enzymol. 82:803-831.

35. Liau, G., and L.M. Chan. 1989. Regulation of extracellular matrix RNA levels in cultured smooth muscle cells. Relationship to cellular quiescence. $J$. Biol. Chem. 264:10315-10320.

36. Sankar, S., N. Mahooti-Brooks, G. Hu, and J.A. Madri. 1995. Modulation of cell spreading and migration by pp125FAK phosphorylation. Am. J. Pathol. 147:601-608.

37. Chan, B.M.C., P.D. Kassner, J.A. Shiro, R. Byers, T.S. Kupper, and M.E. Hemler. 1992. Distinct cellular functions mediated by different VLA integrin $\alpha$ subunit cytoplasmic domains. Cell. 68:1051-1060.

38. Pickering, J.G., C.M. Ford, B. Tang, and L.H. Chow. 1997. Coordinated effects of fibroblast growth factor- 2 on expression of fibrillar collagens, matrix metalloproteinases, and tissue inhibitors of matrix metalloproteinases by hu- 
man vascular smooth muscle cells. Evidence for repressed collagen production and activated degradative capacity. Arterioscler. Thromb. Vasc. Biol. 17:475-482.

39. Elices, M.J., L. Osborn, Y. Takada, C. Crouse, S. Luhowskyj, M.E. Hemler, and R.R. Lobb. 1990. VCAM-1 on activated endothelium interacts with the leukocyte integrin VLA-4 at a site distinct from the VLA-4/fibronectin binding site. Cell. 60:577-584.

40. Hangan, D., S. Uniyal, V. Morris, I. MacDonald, C. von Ballestrem, T. Chau, E. Schmidt, A. Chambers, A. Groom, and B.M.C. Chan. 1996. Integrin VLA-2 $(\alpha 2 \beta 1)$ function in post-extravasation movement of human rhabdomyosarcoma cells in the liver. Cancer Res. 56:3142-3149.

41. Nandan, E., E.P. Clarke, E.H. Ball, and B.D. Sanwal. 1990. Ethyl-3,4dihydroxybenzoate inhibits myoblast differentiation: evidence for an essential role of collagen. J. Cell Biol. 110:1673-1679.

42. Franceschi, R.T., B.S. Iyer, and Y. Cui. 1994. Effects of ascorbic acid on collagen matrix formation and osteoblast differentiation in murine MC3T3-E1 cells. J. Bone Miner. Res. 9:843-854.

43. Franceschi, R.T., and B.S. Iyer. 1992. Relationship between collagen synthesis and expression of the osteoblast phenotype in MC3T3-E1 cells. $J$. Bone Miner. Res. 7:235-246.

44. McCaffrey, T.A., K.B. Pomerantz, T.A. Sanborn, A.M. Spokojny, B. Du, M.-H. Park, J.E. Folk, A. Lamberg, K.I. Kivirikko, D.J. Falcone, et al. 1995. Specific inhibition of eIF-5A and collagen hydroxylation by a single agent. Antiproliferative and fibrosuppressive effects on smooth muscle cells from human coronary arteries. J. Clin. Invest. 95:446-455.

45. Nagler, A., H.-Q. Miao, H. Aingorn, M. Pines, O. Genina, and I. Vlodavsky. 1997. Inhibition of collagen synthesis, smooth muscle cell proliferation, and injury-induced intimal hyperplasia by Halofuginone. Arterioscler. Thromb. Vasc. Biol. 17:194-202.

46. Prockop, D.J., K.I. Kivirikko, L. Tuderman, and N.A. Guzman. 1979. The biosynthesis of collagen and its disorders. N. Engl. J. Med. 301:13-23, 77-85.

47. Huttenlocher, A., R.R. Sandborg, and A.F. Horwitz. 1995. Adhesion in cell migration. Curr. Opin. Cell. Biol. 7:697-706.

48. Felsenfeld, D.P., D. Choquet, and M.P. Sheetz. 1996. Ligand binding regulates the directed movement of $\beta 1$ integrins on fibroblasts. Nature. 383: $438-440$.

49. Miyamoto, S., H. Teramoto, O.A. Coso, J.S. Gutkind, P.D. Burbelo, S.K. Akiyama, and K.M. Yamada. 1995. Integrin function: molecular hierarchies of cytoskeletal and signaling molecules. J. Cell Biol. 131:791-805.

50. Burridge, K., K. Fath, T. Kelly, G. Nuckolls, and C. Turner. 1988. Focal adhesions: transmembrane junctions between the extracellular matrix and the cytoskeleton. Ann. Rev. Cell. Biol. 4:487-525.

51. Miyamoto, S., S.K. Akiyama, and K.M. Yamada. 1995. Synergistic roles for receptor occupancy and aggregation in integrin transmembrane function. Science. 267:883-885.

52. Craig, S.W., and R.P. Johnson. 1996. Assembly of focal adhesions: progress, paradigms, and portents. Curr. Opin. Cell. Biol. 8:74-85.

53. Gilmore, A.P., and K. Burridge. 1996. Regulation of vinculin binding to talin and actin by phospatidyl-inositol-4-5-bisphosphate. Nature. 381:531-534.

54. Huttenlocher, A., M.H. Ginsburg, and A.F. Horwitz. 1996. Modulation of cell migration by integrin-mediated cytoskeletal linkages and ligand-binding affinity. J. Cell Biol. 134:1551-1562.

55. Uitto, J., H.-P. Hoffman, and D.J. Prockop. 1976. Synthesis of elastin and procollagen by cells from embryonic aorta. Differences in the role of hydroxyproline and the effects of proline analogs on the secretion of the two proteins. Arch. Biochem. Biophys. 173:187-200.

56. Rosenbloom, J., and A. Cywinski. 1976. Inhibition of proline hydroxylation does not inhibit secretion of tropoelastin by chick aorta cells. FEBS Lett. 65:246-250.

57. Sastry, S.K., and A.F. Horwitz. 1993. Integrin cytoplasmic domains: mediators of cytoskeletal linkages and extra- and intracellular initiated transmembrane signaling. Curr. Opin. Cell. Biol. 5:819-831.

58. Hotchin, N.A., and A. Hall. 1995. The assembly of integrin adhesion complexes requires both extracellular matrix and intracellular rho/rac GTPases. J. Cell Biol. 131:1857-1865.

59. Stenn, K.S., J.A. Madri, and F.J. Roll. 1979. Migrating epidermis produces $\mathrm{AB}_{2}$ collagen and requires continual collagen synthesis for movement. Nature. 277:229-232.

60. Sibinga, N.E.S., L. Foster, C.-M. Hsieh, M.A. Perrella, W.-E. Lee, W.O. Endege, H. Sage, M.-E. Lee, and E. Haber. 1997. Collagen VIII is expressed by vascular smooth muscle cells in response to vascular injury. Circ. Res. 80:532-541.

61. Hahn, L.H., and K.M. Yamada. 1979. Identification and isolation of a collagen-binding fragment of the adhesive glycoprotein fibronectin. Proc. Natl. Acad. Sci. USA. 76:1160-1163.

62. Hayman, G.C., E. Engvall, and E. Ruoslahti. 1986. Interaction of vitronectin with collagen. J. Biol. Chem. 261:16698-16703.

63. Boucaut, J.C., K.E. Johnson, T. Darribere, D.L. Shi, J.F. Riou, H.B Bache, and M. Delarue. 1990. Fibronectin-rich fibrillar extracellular matrix controls cell migration during amphibian gastrulation. Int. J. Dev. Biol. 34:139-147.

64. Winklbauer, R., and M. Nagel. 1991. Directional mesoderm cell migration in the Xenopus gastrula. Dev. Biol. 148:573-589.

65. Karim, M.A., D.D. Miller, M.A. Farrar, E. Eleftheriades, B. Reddy, C.M. Breland, and A.M. Samarel. 1995. Histomorphometric and biochemical correlates of arterial procollagen gene expression during vascular repair after experimental angioplasty. Circulation. 91:2049-2057. 